\title{
New means of hydrogen storage - the potentials of methanol as energy storage for excessive windpower in North Germany
}

\author{
Johannes Gulden ${ }^{1, *}$, Andreas Sklarow ${ }^{1}$, and Thomas Luschtinetz ${ }^{1}$ \\ ${ }^{1}$ Stralsund University of Applied Sciences, Institute of Renewable EnergySystems, 18435 Stralsund, Germany
}

\begin{abstract}
The aim of the presented project is the technological development of hydrogen storage in methanol. This technology enables the carbon dioxide-based chemical storage of renewable energies as well as a decentralized supply of energy and hydrogen. Additional advantages are the very good compatibility with the existing infrastructure for liquid energy storage as well as the temporal decoupling of energy production and consumption. The latter can be managed independently, thus taking into account the fluctuating nature of wind and solar energy. The centrepiece is the use of new catalysts and processes that enable the chemical reactions in the methanol cycle under mild conditions.
\end{abstract}

\section{Introduction}

Within the frame of a project funded by the German BMWI the Friedrich-Alexander-University ErlangenNürnberg (FAU), the University of Applied Science Stralsund, the Center for Fuelcell Technology in Duisburg (ZBT), the ATI Küste GmbH, and the EnviTec Biogas AG under the coordination of the LeibnizInstitute for Catalysis in Rostock (LIKAT) want to enable the decentralized indirect storage of energy in methanol.

The methanol produced is converted to demandoriented electrical energy in the sense of a temporal and / or interregional energy exchange via the stage of a lowtemperature hydrogen release in a fuel cell. The feasibility of the storage technology according to Figure 1, which also shows the responsibilities in the project consortium, is shown through pilot plants. For the first time, already established technologies such as wind power utilization, electrolysis, $\mathrm{CO}_{2}$-based methanol synthesis, which is the focus in this article, will be combined with the new processes low-temperature reforming of aqueous methanol and direct use of the resulting hydrogen-carbon dioxide gas mixture in a fuel cell.

First a wind turbine with an electrolyzer and the direct dynamic conversion of the hydrogen to methanol is coupled in a conventional synthesis reactor in Stralsund. After storage and transport in a complementary pilot plant at the Erlangen site, the methanol obtained here is converted back into hydrogen and carbon dioxide in a low-temperature process and used directly with a connected PEM fuel cell, including heat extraction, to generate electricity. This symbolizes the possible temporal and spatial separation of energy storage and utilization and minimizes the costs in view of otherwise necessary transport of the reforming plant.
Various $\mathrm{CO}_{2}$ sources are being evaluated for their suitability for methanol synthesis, and biogas-based carbon dioxide is used as an example.

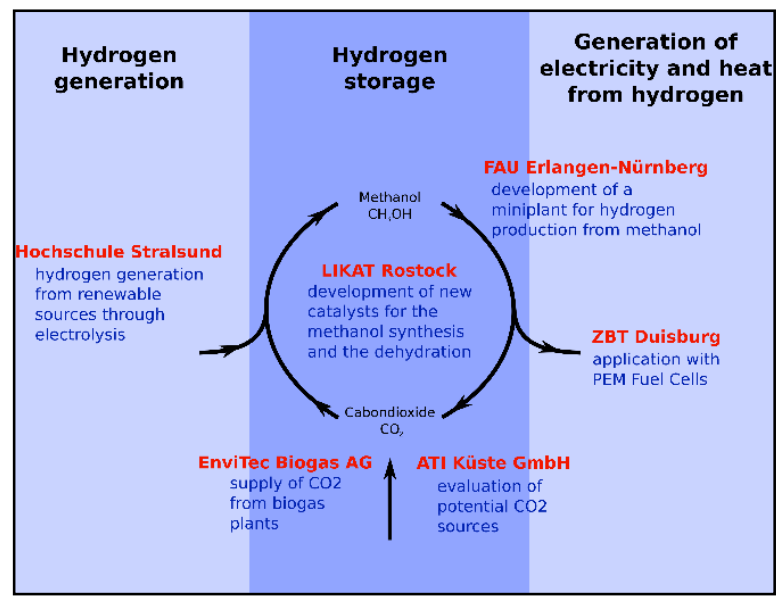

Fig. 1. Schematic drawing of the concept and the partners in the metha cycle project.

The aim of the project partners from Stralsund is a modular simulation of the entire system including the methanol production as well as the reconversion into electrical energy. The new results from within the project consortium will be included to analyse their influence on the system. In the final step a methanol reactor will be built up in Stralsund to demonstrate an efficiency optimized methanol cycle process.

The production of methanol from hydrogen and $\mathrm{CO}_{2}$, is already possible today in processes with heterogeneous catalysts such as copper-zinc oxidealumina at relatively high temperatures of $170-265{ }^{\circ} \mathrm{C}$ and a pressure of 10 to 80 bar. Examples include the "Silicon Fire Methanol Process" (80 bar and $265^{\circ} \mathrm{C}$ ) and the "George Olah $\mathrm{CO}_{2}$ to Renewable Methanol Plant" of

Corresponding author: johannes.gulden@hochschule-stralsund.de 
Carbon Recycling International (ORMP) [1,10]. The Swiss Silicon Fire AG operates since 2010 a mobile demonstration plant for the production of 50 liters of methanol per day with a purity of $99.99 \%$ [2]. Since the end of 2011, ORMP has been producing methanol in Iceland with a current capacity of approx. 4 million liters per year [3]. Further activities exist in Japan at the company Mitsui Chemicals (pilot analysis with 100 annual tons) and in Germany [4]. The dynamic operation with a direct coupling to a wind turbine has never been demonstrated before.

\section{Analysis of the production potential}

The first step is to analyse the production potential for methanol produced from renewable energies. It makes sense to use wind power, which cannot be included in the transmission grid at certain times. Due to the enormous power generation possibilities of wind power in the region, the focus is placed on the direct coupling of wind energy and methanol synthesis. Since there are currently no economic alternatives to the conventional synthesis (see above), the dynamic operation of such a reactor should be adapted and simulated to the wind potentials, which can be adapted in a second step with newly developed catalysts.

Analysing the potential for a future hydrogen infrastructure has to start with the renewable energy potential. According to the Einsman reports [5] 317.57 GWh of electricity were not fed into the grid in 2016 in Mecklenburg Western Pomerania alone. In 2015, there were almost $4725 \mathrm{GWh}$ of renewable electricity in Germany cut due to limitations in the grid. Even the planned grid upgrades will not be sufficient, for a planned corridor of more than $2.8 \mathrm{GW}$ [6] installed wind power per year, to transport the power generated to the consumer. Different storage technologies are therefore in discussion, with power-to-gas being the key technology $[7,8]$. The subsequent storage in liquid methanol is, due to the high energy density and the compatibility with conventional fuels, a possible way to operate a windhydrogen infrastructure economically.

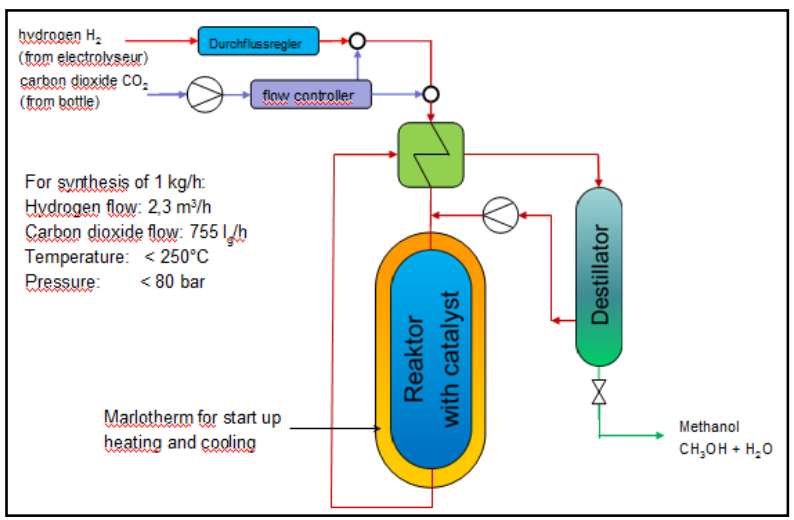

Fig. 2. Schematic drawing of the concept for the methanol synthesis.

With one GWh of electricity, with an efficiency of $75 \%$ in the electrolysis process, $750 \mathrm{MWh}$ of hydrogen will be produced. This corresponds to a volume of 1,250 $\mathrm{m} 3$ at 200 bar. If this hydrogen is now synthesized in an ideal reactor with $83,472 \mathrm{Nm}^{3} \mathrm{CO} 2$ to methanol, about 138,800 liters of synthetic fuel are produced. The reaction proceeds exothermically at 80 bar and $265^{\circ} \mathrm{C}$ [2].

Figure 2 shows the concept of a planned synthesis plant at the University of Applied Sciences Stralsund. The system should be designed so that different operating points are possible. A special focus here is the use of catalysts, which are developed by the project partners.

Following the assumption that the entire non-fed regenerative wind energy will be converted into methanol, future production potentials of up to 34.8 kilotons of methanol will result annually, in Mecklenburg Western Pomerania alone. It is well known that the economics of technologies scale with the number of full load hours, so it can be assumed that the potentials are even greater, because the methanol synthesis plants, in addition to peak shaving, may also contribute to regional value creation and the downstream hydrogen economy.

\section{Simulation of the methanol storage cycle}

The project started to model the methanol storage cycle in a model. The goal is to simulate the entire methanol storage cycle including the regenerative energy generator side and the hydrogenation process as well as the dehydrogenation process and the reconversion. On the basis of the interface and system parameters derived from the simulation and the results of the project partners, the overall system is to be scaled in advance.

In a MATLAB Simulink model, each individual component is simulated as a block, which communicate with one another via suitable interfaces. This makes it possible to customize each component individually and refine the model iteratively. The input for the simulation will be real data from wind turbines and other regenerative power generators.

The results of the project partners are to be included in the simulation as well as the results of the methanol reactor to be built, which will provide for the first time measurement results from the direct coupling with the wind hydrogen chain. The obtained simulation parameters will help to design optimized operating strategies of an economical methanol storage cycle.

\section{Summary and outlook}

The increasingly successful implementation of the energy transition and the associated increase in the share of renewable energies in the coverage of primary energy demand force the development of additional centralized and decentralized long-term power storage technologies in the order of up to $18 \mathrm{GW} / 7.5 \mathrm{TWh}$, due to the fluctuating occurrence of wind and solar energy and the resulting difficulty to calculate a prediction of these forms of energy. Already at about $40 \%$ share of 
renewable energies in electricity consumption, which were planned in the Federal Government's Energy Concept 2050 for the year 2015, existing and new transmission and distribution grids alone are unable to compensate for the temporal and regional imbalances in production and consumption [9]. In addition, individual regions in Germany, such as Mecklenburg Western Pomerania, will achieve up to $100 \%$ coverage of renewable energy in the electricity sector already much earlier.

For the long-term storage of large amounts of energy chemical storage systems are predestined. The generation of hydrogen in electrolyzers using renewable energy sources, such as wind energy and photovoltaic systems is a first step in this context. However, this creates the downstream problem of storing the regeneratively generated hydrogen. Previous technologies such as cryogenic, pressure or storage in metal hydrides have low gravimetric energy densities and the energy required for liquefaction and compression leads to additional energy losses of up to $30 \%$.

A promising alternative is liquid high-energy chemical storage systems. Following the example of nature, where solar energy is largely bound in the form of carbohydrates, suitable substances can take over this task in an alternative material and energy cycle based on renewable hydrogen. Particularly suitable for this purpose is methanol accessible by hydrogenation of carbon dioxide.

\section{References}

1. G. Olah, Angewandte Chemie, 125, 112 (2013)

2. http://www.silicon-fire.com/projekte-text.php, last visited on 13/07/2018

3. G. K. S. Prakash, Workshop Sustainable Fuels from Renewable Energies, IASS Potsdam, Germany (2013)

4. F. Pontzen, W. Liebner, V. Gronemann, M. Rothaemel, B. Ahlers, Catal. Today, 171, 242 (2011)

5. https://www.bundesnetzagentur.de Quartalsbericht Gesamt 2016

6. EEG 2017

7. J. Lehmann, T. Luschtinetz, Wasserstoff und Brennstoffzellen - Unterwegs mit dem sauberen Kraftstoff, ISBN 978-3-642-34668-2, Springer (2014)

8. NOW-Elektrolyse-Studie, short version, $36 \mathrm{ff}$ (2011)

9. Verband der Elektrotechnik-ElektronikInformationstechnik (VDE), Energiespeicher für die Energiewende (2012)

10. M. He, Y. Sun, B. Han, Angewandte Chemie, 125, $9798(2013)$ 